\title{
Erzincan ili elma ağaçlarında bulunan zararlı ve faydalı böcek türleri ile bazı önemli zararlı türlerin doğada görülme zamanı
}

\author{
İsmail Alaserhat ${ }^{1 *}$ \\ ${ }^{1}$ Bahçe Kültürleri Araştırma Enstitüsü Müdürlüğü, Erzincan, Türkiye (ORCID: 0000-0002-6929-0179)
}

(Illk Geliş Tarihi 2 Aralık 2019 ve Kabul Tarihi 31 Aralık 2019)

(DOI: 10.31590/ejosat.653944)

\begin{abstract}
ATIF/REFERENCE: Alaserhat, İ. (2019), Erzincan İli Elma Ağaçlarında Bulunan Zararlı ve Faydalı böcek Türleri ile Bazı Önemli Zararlı Türlerin Doğada Görülme Zamanı, (17), 1116-1124.

$\ddot{\mathbf{O z}}$

Bu çalışma, 2011-2013 yılları arasında Erzincan ili elma alanlarındaki fitofag ve faydalı türler ile bazı önemlilerin doğada görülme zamanı belirlemek amacıyla yürütülmüştür. Örneklemelerde elma bahçelerinde ağaç dallarına yapılan darbe yöntemi ve türlere özgü eşeysel çekici tuzaklar kullanılmıştır. Ayrıca ergin öncesi dönemde olanlar ve parazitoit türler için kültüre alma yöntemi kullanılmıştır. Çalışma sonuçlarına göre, elma bahçelerinde fitofag türlerden 25 böcek ve 1 akar ile genel predatör ve parazitoitlerden 21 faydalı böcek türü saptanmıştır. Zararlı türlerden Cydia pomonella (Linnaeus), Archips rosana (Linnaeus), Aphis pomi de Geer, Eriosoma lanigerum (Hausmann), Lepidosaphes ulmi (Linnaeus), Tropinota (Epicometis) hirta (Poda), Anthonomus pomorum (Linnaeus), Polydrusus ponticus Faust ve Tetranychus urticae Koch.’un ekonomik yönden zararlı olduğu gözlenmiştir. Bununla birlikte Adalia bipunctata (Linnaeus), Adalia fasciatopunctata revelieri (Mulsant), Coccinella semtempunctata (Linnaeus), Oenopia (Synharmonia) conglobata (Linnaeus) (Coleoptera: Coccinellidae), Episyrphus balteatus De Geer (Diptera: Syrphidae), Chrysoperla carnea (Stephens) (Neuroptera: Chrysopidae) ve Aphelinus mali (Haldeman) (Hymenoptera: Aphelinidae) en fazla görülen yararlı türler olarak belirlenmiştir. Zararlı türlerden olan Elma içkurdu (C. pomonella) erginlerinin mayıs-eylül, Elma yeşil yaprakbiti (A. pomi) ergin ve nimflerinin mayıs-ekim, İki noktalı kırmızı örümcek (T. urticae) ergin ve nimflerinin mayıs-ekim, Baklazınnı (T. hirta) erginlerinin mayıs ayı içerisinde ve Elma gözkurdu (A. pomorum) erginlerinin ise nisan sonu-mayıs başı döneminde doğada görüldüğü tespit edilmiştir.
\end{abstract}

Anahtar Kelimeler: Elma, Zararlılar, Parazitoit, Predatör, Erzincan.

\section{Phytophagous and beneficial species on apple trees, time to be seen some important species in nature in Erzincan province}

\begin{abstract}
The study was conducted in 2011-2013, with the purpose of determining the phytophagous and beneficial species in apple orchards and time to be seen of some important pests in nature in Erzincan provinces. In the samplings, the impact method applied to tree branches and sexually attractive traps specific to the species were used in apple orchards. In addition, cultivation method was used for pre-adult and parasitoid species. According to the results of the study, it was determined that 25 insects and 1 mite from phytophagous species and 21 beneficial insect species from general predators and parasitoids in apple orchards. It was observed that Cydia pomonella (Linnaeus), Archips rosana (Linnaeus), Aphis pomi de Geer, Eriosoma lanigerum (Hausmann), Lepidosaphes ulmi (Linnaeus), Tropinota (Epicometis) hirta (Poda), Anthonomus pomorum (Linnaeus), Polydrusus ponticus Faust and Tetranychus urticae Koch, which were harmful species, were economically harmful. However, Adalia bipunctata (Linnaeus), Adalia fasciatopunctata revelieri (Mulsant), Coccinella semtempunctata (Linnaeus), Oenopia (Synharmonia) conglobata (Linnaeus) (Coleoptera: Coccinellidae), Episyrphus balteatus De Geer (Diptera: Syrphidae), Chrysoperla carnea (Stephens) (Neuroptera: Chrysopidae) and Aphelinus mali (Haldeman) (Hymenoptera: Aphelinidae) were identified as the most useful species. It was determined that, some important phytophagous species respectively in May-September of C. pomonella adults, in May-October of $A$. pomi adult and nymphs, in May-October of T. urticae adult and nymphs, in May T. hirta adults and in end of April-early May of A. pomorum adults were seen in the nature
\end{abstract}

Key words: Apple, Pests, Parasitoid, Predator, Erzincan.

* Sorumlu Yazar: Bahçe Kültürleri Araştırma Enstitüsü Müdürlüğü, Erzincan, Türkiye, ORCID: 0000-0002-6929-0179, $\underline{\text { _alaserhat36@ hotmail.com }}$ 


\section{Giriş}

Ilıman iklim meyve türleri içerisinde yer alan elmanın anavatanı, Anadolu da dâhil olmak üzere Güney Kafkasya’ya uzanmakta ve kültürü milattan öncelere kadar dayanmaktadır. Türün farklı ekolojilere uyum kabiliyetinin yüksek olması, dünya üzerinde geniş bir yayılım göstermesine neden olmuştur. Dolayısıyla elma; toplam dünya meyve endüstrisinin yaklaşı \%13'ünü oluşturmakta ve muz, üzüm ve portakaldan sonra 4. büyük tür olarak karşımıza çıkmaktadır (Karamürsel, 2009). Dünya elma üretimi 83.139.326 ton olup Türkiye 3.032.164 ton ile dünya elma üretiminde Çin ve ABD’den sonra üçüncü sırada yer almaktadır (Anonymous, 2017).

Ülke ekonomisi ve halkın beslenmesi açısından önemli ürünlerden biri olan elmanın büyük bir bölümü taze olarak tüketilmekte; başta meyve suyu, konsantresi ve püresi olmak üzere sirke, pekmez, reçel, marmelat, çay, cips ve elma kurusu gibi yan ürünleri de elde edilebilmektedir (Anonim, 2011).

Elma meyvesi, yüksek antioksidan aktiviteye sahip olduğundan lipit oksidasyonunu azaltmada, kolesterolu düşürmede ve kanser hücrelerinin çoğalmasını engellemede çok etkindir. Elmada kuersetin, kateşin, epikateşin, prosiyanidin, klorojenik asit, gallik asit, floridizin, betakaroten gibi güçlü antioksidanlar vardır. Elmada bulunan fitokimyasalların insan sağlığına olan etkileri oldukça geniş ve yararlıdır. Bir İsveç atasözü vardır. "Her gün bir elma ye, bir doktoru uzaklaştır." (Bulantekin ve Kuşcu, 2017).

Ülkemizde elmada zararlı olan zararlı böcekler ve doğal düşmanları üzerine İren, 1977; Düzgüneş ve Toros, 1978; Yiğit ve Uygun, 1982; Çiftçi ve ark., 1985; Özkan, 1986; Erden, 1988; Kıroğlu, 1992; Çiftçi ve ark., 1995; Özbek ve ark., 1998; Zeki ve ark., 1998; Bozbek ve ark., 2009; Karaca et al., 2010; Bozbek 2012; Canbay ve Tozlu, 2013; Alaserhat, 2015; Yaman ve ark., 2016; Küçükballı ve Karaca, 2018 gibi bir çok sayıda araştırıcı çalışma yürütmüş ve elmada 70'in üzerinde zararlı böcek türü olduğunu bildirmişlerdir. Araştırıcılar, bunlardan bazılarının çiçek, tomurcuk ve meyvelerde bazılarının da hem yapraklarda beslenmesi hem de yaprakları bükmesi ve ağacın kök, gövde dalların içinde beslenerek önemli zararlara neden olduklarını belirtmişlerdir.

Çalışmanın yürütüldüğ̈̈ Erzincan ilinde elma bahçelerinde üretimi sınırlayan önemli etkenlerden birisi bitki koruma sorunlarıdır. Nitekim yapılan araştırmalar ve bölge illerindeki ilgili tarım kuruluşlardan ve üreticilerden edinilen bilgiler sonucu, elma zararlılarının bölgede önemli oranda zarara sebep olduğu pestisit kullanımının giderek arttığı belirlenmiştir. Bölgedeki elma bahçelerinde bulunan bu zararlı böcek türlerinin, ekonomik yönden önemli oranda zarara neden olduğu gözlemlenmiştir. Son zamanlarda bölgede meyve bahçelerinde zararlı organizma türleri ile mücadelede gelişi güzel pestisit kullanımının sonucunda var olan doğal denge bozulacak, buda ileriki yıllarda zararlıların salgın yapma ihtimalini arttıracaktır. Mevcut olan bu olumsuz durumun iyileştirilmesi hem çevre ve insan sağlı̆̆ hem de kaliteli ürünün piyasaya sunulması açısından önemlidir. Bu nedenle sürdürülebilir tarımsal üretim ve kalkınmayı sağlamak için entegre mücadele sisteminin uygulanması gerekmektedir.

$\mathrm{Bu}$ çalışma sonucunda elma bahçelerindeki zararlı türler ile etkili bir mücadele yapabilmek için gerekli olan elma plantasyonlarındaki türlerin belirlenmesi, doğada görülme zamanı ve zarar şekli ortaya konulmuştur.

\section{Materyal ve Metot}

\subsection{Materyal}

Çalışmanın ana materyalini Erzincan ili Merkez ve Üzümlü ilçelerinde bulunan elma bahçeleri ile bu bahçelerden toplanan farklı türlere ait gerek ergin ve gerekse ergin öncesi dönemler oluşturmuştur. Ayrıca türlere göre değişmekle beraber farklı feromon tuzaklar, kültür kapları, stereomikroskop, preparasyon için kullanılan lam-lamel, böcek iğneleri, ephendorf tüpleri vb. malzemeler çalışmanın diğer materyallerini oluşturmuştur.

\subsection{Metot}

\subsubsection{Doğa Çalışmaları}

Erzincan ili Merkez ilçeye bağlı Bahçeliköy, Cevizli köyleri; Dörtler ve Yalnızbağ beldeleri ile Üzümlü ilçesine bağlı Üzümlü Merkez ve Bayırbağ köyünden birer bahçe olmak üzere 6 elma bahçesinde sürveyler yapılmıştır (Çizelge 1). Çalışma, tesadüfi örnekleme yöntemine göre ildeki toplam ağaç sayısının \% 0.1'i esas alınarak yürütülmüştür (Bora ve Karaca, 1970). Elma bahçelerinde 2011-2013 yılları arasında vejetasyon süresi boyunca haftada bir kez örnekler düzenli aralıklarla alınmıştır. Örneklemelerde bahçelerin ilaçlanmamış ve bakımsız olmasına özen gösterilmiş ve her bahçede incelenen ağaç sayısı Grigorov (1974)'a göre belirlenmiştir. Bu yönteme göre; 20 ağaç olan bahçelerde bütün ağaçlar, 21-70 ağaç olanlarda 21-30, 71-150 ağaç olanlarda 31-40, 151-300 ağaç olanlarda 41-80, 301-1000 ağaç olanlarda ağaçların \%15'i kontrol edilmiştir.

Çizelge 1. Çalışmaların yürütüldüğü bahçeler ve ağaç sayıları

\begin{tabular}{llcc}
\hline İlçeler & Köyler ve beldeler & Bahçedeki ağaç sayısı & İncelenen ağaç sayısı \\
\hline \multirow{4}{*}{ Merkez } & Bahçeliköy & 50 & 25 \\
& Cevizli & 500 & 75 \\
& Dörtler & 40 & 25 \\
\multirow{2}{*}{ Üzümlü } & Yalnızbağ & 50 & 25 \\
\hline
\end{tabular}

\subsubsection{Göz ile inceleme yöntemi}

Vejetasyon süresince elma ağaçlarında var olan zararlı ve faydalı böcekleri saptamak amacıyla haftalık aralıklarla, bahçeyi temsil edecek şekilde Grigorov (1974)'a göre yeterli sayıda elma ağacının kök boğazı, gövde, dal, sürgün, yaprak, tomurcuk, çiçek ve 
meyveleri 10 büyütmeli lup ile dikkatlice incelenmiştir (Anonim, 2008). Gerekli görüldüğünde, bu bitki parçaları polietilen torbalara konularak laboratuvara getirilmiş ve burada stereo mikroskop altında incelemeleri yapılmıştır.

\subsubsection{Darbe yöntemi}

$\mathrm{Bu}$ yöntem ağaçların üzerinde bulunan ve hareketli olan zararlı, faydalı türlerin belirlenmesi için kullanılmış olup vejetasyon süresince haftalık aralıklarla uygulanmıştır. Örneklemenin yapılacağı bahçelerdeki ağaç sayısına göre, bahçeyi temsil edecek şekilde tesadüfen seçilmiş ağaçların dört yönünden birer dalına üzeri lastik hortumla kaplı sopa ile üç kez aynı hızla vurularak (toplam 100 darbede) hareketli olan zararlı ve yararlıların steiner hunisine düşmeleri sağlanmıştır (Anonim, 2008). Darbe aletinin dibinde bulunan öldürme şişesinde toplanan türler, önce etil asetatla öldürülmüş daha sonra petri kutusuna konularak laboratuvara getirilmiş, tasnif edilmiş, etiketlenmiş ve teşhise gönderilmiştir.

\subsubsection{Dal sayımı ve kültüre alma yöntemi}

Kışı ağaç üzerinde geçiren kabuklubit, koşnil gibi zararlıları ve yaprakbiti türlerinin parazitoitlerini saptamak amacı ile elma bahçelerinden sürgün ve dal örnekleri alınmıştır. Bu amaçla yaklaşık olarak $20 \mathrm{~cm}$ uzunluğundaki birer dal parçası veya sürgün kesilerek, bir kese kâğıdına veya polietilen torbaya konulmuş ve buz kutusu içinde laboratuvara getirilmiştir. Bu dallar, laboratuvarda bir stereomikroskop altında incelenerek gerekli incelemeler yapıldıktan sonra, diğer zararlılardan ve artıklardan temizlenerek oda koşullarında $\left(25^{\circ} \mathrm{C}\right.$ sıcaklık ve \%60-80 orantılı nem) parazitoit çıkartma kutularında kültüre alınmıştır (Anonim, 2008). Elde edilen ergin parazitoit böcekler aspiratör ve yumuşak pens yardımıyla \%90'lık etil alkol bulunan ephendorf tüplerin içine alınmış ve teşhise gönderilmiştir.

\subsubsection{Feromon tuzakların kullanımı}

Erzincan ili Merkez ve Üzümlü ilçesine bağlı birer bahçede zararlı Tortricidae familyasına bağlı türleri belirlemek amacı ile Pherocon tipi eşeysel çekici tuzaklar kullanılmıştır. Tuzaklar ağaçlarının güney doğu yönüne, yerden 1,5-2 metre yüksekliğe ve hâkim rüzgâr yönüne asılmıştır. Tuzak kapsülleri, prospektüsüne uygun olarak 4-6 haftalık aralıklarla değiştirilmiştir (Anonim, 2008; Canbay ve Tozlu, 2013). Vejetasyon boyunca asılı olan tuzaklar haftalık olarak kontrol edilmiş, kirlenen yapışkan tablaları yenileri ile değiştirilmiştir.

\subsubsection{Laboratuvar Çalışmaları}

Bahçelerden toplanan böcekler ve akar türü laboratuvarda önce birbirlerine benzerliklerine göre gruplandırılarak numaralandırılmıştır. Bununla birlikte yaprakbitleri (afit) gibi yumuşak vücutlu olan bireyler \% 70 'lik alkol içine alınmıştır. Ergin öncesi dönemde bulunan bireyler ise bulundukları bitki kısmıyla beraber laboratuvarda ayrı ayrı kültür kafeslerine alınarak ergin elde edilmeye çalışılmıştır. Daha sonra böcekler takım, familya ve türlerine göre iğnelenip, etiketlenerek uygun kutulara alınmış tanılanmaları için konu uzmanlarına gönderilmiştir.

\section{Araştırma Sonuçları ve Tartışma}

\subsection{Zararlı türler}

Çalışma sonuçlarına göre örnekleme bahçelerinde fitofag türlerden 25 böcek ve 1 akar olmak üzere toplam 26 zararlı tür tespit edilmiştir (Çizelge 2). Saptanan zararlı türlerden Cydia pomonella (Linnaeus), Archips rosana (Linnaeus), Aphis pomi de Geer, Eriosoma lanigerum (Hausmann), Lepidosaphes ulmi (Linnaeus), Tropinota (Epicometis) hirta (Poda), Anthonomus pomorum (Linnaeus), Polydrusus ponticus Faust ve Tetranychus urticae Koch.'un ekonomik yönden zararlı olduğu gözlenmiştir. 
European Journal of Science and Technology

Çizelge 2. Erzincan ili elma ağaçlarında 2011-2013 yıllarında belirlenen zararlı böcek ve akar türleri

\begin{tabular}{|c|c|c|}
\hline Takım & Familya & Tür \\
\hline \multirow[t]{4}{*}{ Acarina } & Tetranychidae & Tetranychus urticae (Koch) \\
\hline & & Aphis pomi de Geer \\
\hline & & Brachycaudus helichrysi (Kaltenbach) \\
\hline & Aphididae & Dysaphis devecta (Walker) \\
\hline \multirow[t]{9}{*}{ Hemiptera } & & Dysaphis (Pomaphis) plantaginea (Passerini) \\
\hline & & Eriosoma lanigerum (Hausmann) \\
\hline & Disanididos & Diaspidiotus perniciosus (Comstock) \\
\hline & Diaspididae & Lepidosaphes ulmi (Linnaeus) \\
\hline & Scarabaeidae & Tropinota (Epicometis) hirta (Poda) \\
\hline & & Anthonomus amygdali Hustache \\
\hline & & Anthonomus pomorum (Linnaeus) \\
\hline & & Ceutorhynchus picitarsis Gyllenhal \\
\hline & Curculionidae & Magdalis ruficornis (Linnaeus) \\
\hline \multirow[t]{9}{*}{ Coleoptera } & & Phyllobius glaucus (Scopoli) \\
\hline & & Polydrusus ponticus Faust \\
\hline & & Sibinia primita (Herbst) \\
\hline & & Rhynchites auratus (Scopoli) \\
\hline & Rhynchitidae & Rhynchites bacchus (Linnaeus) \\
\hline & Scolytidae & Scolytus rugulosus (Müller) \\
\hline & & Archips podana (Scopoli) \\
\hline & & Archips rosana (Linnaeus) \\
\hline & Tortricidae & Archips xylosteana (Linnaeus) \\
\hline \multirow[t]{4}{*}{ Lepidoptera } & & Cydia pomonella (Linnaeus) \\
\hline & Lasiocampidae & Malacosoma neustria (Linnaeus) \\
\hline & Nepticulidae & Stigmella malella (Stainton) \\
\hline & Yponomeutidae & Yponomeuta malinellus Zeller \\
\hline
\end{tabular}

Ülkemiz elma alanlarında yapılan çeşitli çalışmalarda; Yiğit ve Uygun (1982), Adana, Mersin ve Kahramanmaraş illeri elma bahçelerinde zararlı ve faydalı türlerin belirlenmesi üzerine yürüttükleri çalışma sonucunda, 6 takıma ait 42 familyaya bağlı 132 fitofag tür belirlemişler ve bunlardan 38'inin elma bahçelerinde zararlı türler olduğunu ifade etmişlerdir. Çiftçi ve ark. (1985), Antalya ili elma bahçelerindeki önemli zararlılar ile doğal düşmanlarının tespiti üzerine yapmış oldukları çalışmada, C. pomonella, Phyllonorycter gerdsimowi Hering, Leucoptera malifoliella Costa, A. pomi, D. plantaginea, E. lanigerum, L. ulmi, Tetranychus viennensis Zacher ve Cenopalpus pulcher Canestrini et Fanzaga'i elma bahçelerindeki önemli zararlı türler olarak tespit etmişlerdir. Erden (1988), Erzincan bölgesi (Erzincan, Sivas, Gümüşhane, Tunceli-Pertek, Erzurum-İspir ve Kars-Kağızman) yumuşak çekirdekli meyve ağaçlarında yapmış olduğu çalışma sonucunda 45 zararlı tür tespit etmiş bunlardan 34 türün elmada zararlı olduğunu saptamıştır. Ayrıca araştırıcı bu türlerden 8 türün zarar ve yoğunluk açısından elmada önemli türler olduğunu belirtmiştir. Yanar ve Ecevit (2005), Tokat ili elma bahçelerinde görülen bitki zararlısı ve predatör akar türlerinin belirlenmesi üzerine yürüttükleri çalışma sonucunda T. urticae'nında içinde yer aldığı Tetranychidae familyasından 5, Eriophyidae familyasından 2, Tarsonemidae ve Tenuipalpidae familyalarından birer tür olmak üzere toplam 9 zararlı; Phytoseiidae familyasından 7 ve Stigmaeidae familyasından 1 tür olmak üzere toplam 8 faydalı akar türü belirlemişlerdir. Ayaz ve Yücel (2010), Elazı̆̆ ili elma alanlarında yürüttükleri çalışma sonucunda 6 takıma bağlı 20 familyaya ait 31 zararlı arthropod türü ile 3 takıma bağlı 4 familyaya ait 7 faydalı böcek türü tespit etmişlerdir. Karaca et al. (2010), Isparta ili elma bahçelerinde yürütmüş oldukları çalışmada 4 takıma ait 19 zararlı tür saptamışlardır. $\mathrm{Bu}$ türler içerisinde yer alan elma iç kurdunun (C. pomonella), Isparta ili elma bahçeleri için ana zararlı olduğunu ifade etmişlerdir. Bozbek (2012), Erzincan ilinde elma ağaçlarında görülen Coccoidea (Hemiptera) üst familyasına ait 3 tür belirlemiş olup bunlardan D. perniciosus'un diğer türlere göre daha yoğun ve yaygın olarak bulunduğunu ifade etmiştir. Küçükballı ve Karaca (2018), Isparta ilinde yürüttüğü çalışma sonucunda $C$. pomonella, A. pomi, D. plantaginea, T. urticae ve Pananychus ulmi (Koch.)'nin elma bahçelerinde önemli zararlılar olduğunu ifade etmişlerdir.

\subsection{Faydalı türler}

Örneklemeler, elma bahçelerindeki zararlı organizmaların doğal düşman türlerini belirlemek amacıyla yapılmıştır. Bu amaçla elma bahçelerinden toplanan ve laboratuvarda kültüre alınan zararlı ile bulaşık bitki örneklerinde parazitoit ve predatörler saptanmaya çalışılmıştır. Elma bahçelerinde ağaç dallarına yapılan darbe yöntemi yanı sıra parazitlenmiş örneklerin kültüre alınması ile elde edilen genel predatör ve parazitoitlerden olan 6 takıma bağlı 9 familya ait 21 faydalı böcek türü saptanmıştır (Çizelge 3). 
Avrupa Bilim ve Teknoloji Dergisi

Çizelge 3. Erzincan ilinde 2011-2013 yıllarında elma bahçelerinde belirlenen genel predatör ve parazitoit türleri

\begin{tabular}{|c|c|c|}
\hline Takım & Familya & Tür \\
\hline \multirow[t]{2}{*}{ Dermaptera } & Forficulidae & Forficula auricularia Linnaeus \\
\hline & & Anthocoris nemoralis (Fabricus) \\
\hline \multirow[t]{2}{*}{ Hemiptera } & Anthocoridae & Orius minutus (Linnaeus) \\
\hline & Miridae & Deraecoris (Knightocapsus) lutescens (Schilling) \\
\hline \multirow[t]{5}{*}{ Neuroptera } & Chrysopidae & Chrysoperla carnea (Stephens) \\
\hline & & Adalia bipunctata (Linnaeus) \\
\hline & & Adalia fasciatopunctata revelieri (Mulsant) \\
\hline & & Chilocorus bipustulatus (Linnaeus) \\
\hline & & Coccinella quatuordecimpustulata (Linnaeus) \\
\hline \multirow[t]{5}{*}{ Coleoptera } & Coccinellidae & Coccinella semtempunctata (Linnaeus) \\
\hline & & Oenopia (Synharmonia) conglobata (Linnaeus) \\
\hline & & Psyllobora vigintiduopunctata (Linnaeus) \\
\hline & & Scymnus pallipediformis (Günther) \\
\hline & & Stethorus punctillum (Weise) \\
\hline \multirow{3}{*}{ Diptera } & Syrnhidae & Episyrphus balteatus De Geer \\
\hline & тугрпшиас & Eupeodes corollae Fabricius \\
\hline & Chamaemyiidae & Leucopis sp. \\
\hline \multirow{4}{*}{ Hymenoptera } & & Aphidius abjectus (Haliday) \\
\hline & Braconidae & Praon volucre (Haliday) \\
\hline & & Trioxys pallidus (Haliday) \\
\hline & Aphelinidae & Aphelinus mali (Haldeman) \\
\hline
\end{tabular}

Yiğit ve Uygun (1982), Adana, Mersin ve Kahramanmaraş illeri elma bahçelerinde yürüttükleri çalışma sonucunda, 7 takıma ait 21 familyaya bağlı toplam 67 faydalı tür tespit etmişlerdir. Çiftçi ve ark. (1985), Antalya ili elma bahçelerindeki önemli zararlılar ile doğal düşmanlarının tespiti üzerine yapmış oldukları çalışmada, 15 predatör ve 1 parazitoit ile birlikte toplam 16 faydalı böcek türü bulduklarını bildirmişlerdir. Özdemir ve Özdemir (2002), Orta Anadolu Bölgesinde 1984-2001 yılları arasında Archips türlerinde (Lepidoptera: Tortricidae) saptanan Ichneumonidae (Hymenoptera) familyasına ait türler ile ilgili yaptıkları çalışmada toplam 14 parazitoit türü saptamışlardır. Piekarska-Boniecka ve ark., (2008), tarafından 2004 ve 2007 yıllarında Polonya'daki elma bahçelerinde A. rosana'nın parazitoit tür kompozisyonu ve parazitlenmesi üzerine yaptıkları çalışmada A. rosana pupasının Ichneumonidae, Chalcidoidea (Hymenoptera) ve Tachinidae (Diptera) gruplarının parazitoitleri ile parazitlendiğini belirlemiş̧lerdir. Yardım ve ark. (2003), Van ili elma bahçelerinde yürütmüş oldukları çalışma sonucunda, 13 adet predatör tür tespit saptamışlardır. Bozbek (2012), Erzincan ilinde elma ağaçlarında görülen Coccoidea (Hemiptera) üst familyasına ait 3 tür belirlemiş olup bunlar üzerinde $C$. carnea (Chrysopidae), Exochomus quadripustulatus (Linnaeus), A. bipunctata, A. fasciatopunctata revelieri, C. bipustulatus, C. septempunctata, C. quatuordecimpustulata, O. conglobata, S. punctillum, S. pallipediformis (Coccinellidae), teşhisi yapilamayan Cecidomyiidae familyasına ait bir tür olmak üzere 11 predatör ile Pteroptrix sp. nr. longiclava, Prospaltella perniciosi, Coccophagoides similis, Prospaltella sp. ve Aphytis sp. (Aphelinidae) olmak üzere 5 parazitoit tür tespit etmiş̧ir. Alaserhat (2015), Erzincan ve Gümüşhane illerinde elma ağaçlarında 9 adet yaprakbiti tespit etmiş olup, bu yaprakbitleri üzerinde beslenen Forficulidae (1), Anthocoridae (5), Miridae (1), Chrysopidae (3), Raphidiidae (1), Coccinellidae (20), Syrphidae (5), Chamaemyiidae (1), Hybotidae (1) familyalarından 38 adet predatör ile Braconidae (7) ve Aphelinidae (1) familyalarından 8 adet parazitoit olmak üzere toplam 46 adet faydalı tür tespit etmiştir. Mdellel ve Ben Halima Kamel (2015), Tunus'ta elma bahçelerinde 2013-2015 yıllarında yapmış oldukları çalışma sonucunda A. pomi, D. plantaginea ve E. lanigerum olmak üzere 3 adet yaprakbiti tespit etmiş olup, bunlar üzerinde beslenen Coccinellidae (2), Syrphidae (2), Cecidomyiidae (1) familyalarından 5 predatör tür ile Braconidae familyasından 1 parazitoit tür olmak üzere toplam 6 doğal düşman tür belirlemişlerdir. Porcel ve ark. (2018), İsveç'in güneyindeki Scania'daki elma bahçelerinde yürütmüş oldukları çalışma sonucunda Forficulidae, Anthocoridae, Chrysopidae, Coccinellidae, Cantharidae ve Cecidomyiidae familyalarına giren 18 predatör tür tespit etmişlerdir.

Tespit edilen faydalı türlerden olan Braconidae ve Aphelinidae familyalarına giren parazitoit türler, çalışma süresince belirlenen yaprakbiti türlerinde elde edilmiştir. Çalışmanın yürütüldüğü elma bahçelerinde bulunan ve genel predatörlerden biri olan Coccinellidae familyasına ait 9 tür tespit edilmiştir. Bu türlerden A. bipunctata, A. fasciatopunctata revelieri, C. semtempunctata ve $O$. conglobata türleri Erzincan ilindeki elma alanlarında yoğun olarak bulunmuştur. Çalışmanın yapıldı̆̆ı elma bahçelerinde Syrphidae familyasına bağl $E$. balteatus ve $E$. corollae türleri belirlenmiştir. Ayrıca sürvey yapılan elma alanlarında yoğun şekilde Chrysopidae familyasına ait Chrysoperla carnea'nın ergin ve larvaları saptanmıştır.

Bozbek (2012) elma alanlarında; Kaplan ve Yücel (2014) çilek alanlarında; Kaplan ve Bayhan (2014) bağ alanlarında; Kaplan ve ark. (2016) zeytin bahçelerinde; Alaserhat ve Güçlü (2016) kuşburnu alanlarında; Alaserhat ve Canbay (2017) biber alanlarında; Alaserhat ve Kaplan (2017) akasya alanlarında zararlı böcek türleri ile bir arada bulunan predatörlerden Anthocoridae familyasından Orius minutus, Chrysopidae familyasından Chrysoperla carnea, Nabidae familyasından Nabis punctatus Costa, Reduvidae familyasından Nagusta goedeli Kolenatil, Coccinellidae familyasından Adalia bipunctata, A. decempunctata (Linnaeus), A. fasciatopunctata revelieri, Chilocorus bipustulatus, Coccinella semtempunctata, C. undecimpunctata L., Exochomus quadripustulatus, Hippodamia variegata Goeze, Oenopia (Synharmonia) conglobata, Stethorus sp. ve Scymnus sp., Syrphidae familyasından Episyrphus balteatus, Eristalis arbustorum L. ve Eupeodes corollae'yi tespit ettiklerini ve bu türleri söz konusu bitkisel üretim alanlarında yaygınlık ile yoğunluk açısından önemli bulduklarını bildirmişlerdir. 
Daha önceden yapılan çalışmalarda Cranshaw (2004), C. carnea erginlerinin nektar ve polen ile beslendiğini, larvalarının ise thrips, yaprakbiti ve kü̧̧ük tırtılların predatörü olduğunu bildirmiştir. Öncüer (1991), C. carnea'nın yaprakbitleri üzerinde ciddi etkileri olduğunu belirtmiştir. Ayrıca Kaya ve Öncüer (1988) ve Yoldaş (1994), C. carnea'nın polifag bir tür olduğu, larvalarının thripsler, yaprakbitleri, bazı kabuklubitler, lepidopter yumurta ve larvaları, pysillidler, Chrysomelidae familyasına bağlı larvalar, bazı akar türleri ve beyazsinekler ile beslendiğini bildirmişlerdir.

\subsection{Bazı önemli zararlı türlerin doğada görülme zamanı}

Çalışmanın yürütüldüğ̈̈ elma bahçelerinde 26 zararlı türden en yoğun olarak Lepidoptera takımının Tortricidae familyasından $C$. pomonella başta olmak üzere 4 adet Tortricidae türü belirlenmiştir. Belirlenen bu türlerden olan ve elma bahçelerinin ana zararlısı konumunda olan Elma içkurdu (C. pomonella)'nun erginleri Mayıs ayının ikinci haftasında itibaren eşeysel çekici tuzaklarda görülmeye başlanmış olup, son olarak ise Eylül ayının ilk haftasında tuzaklarda yakalanmıştır. Ergin kelebeklerin doğadaki uçuş periyodunun yaklaşık olarak 4 ay kadar sürdüğü saptanmıştır. Gerek eşeysel çekici tuzaklarda yapılan ergin sayımları ve gerekse de vuruklu meyve incelemeleri sonucunda zararlının Erzincan ilinde iki döl verebildiği kanısına varılmıştır. Larvalar doğrudan meyvede zarar yapmakta, meyveyi delerek galeriler açmakta, meyvenin etli kısmını ve çekirdek evini yemekte ve meyve içerisinde beslenme artıkları bırakmaktadır. Tüm bu zararları sonucunda da meyve dökümlerine yol açmaktadır. Elma içkurdu zararına uğrayan meyvelerin kalite ve kantitesi düşmektedir. Güçlü ve Özbek (1995), Erzurum'da elma ağaçlarında çiçek ve meyvedeki zararlılar üzerine yürüttükleri çalışma sonucunda $C$. pomonella'nın meyvelerde \% 65 (40-80) oranında kurtlanmaya sebep olduğunu ifade etmişlerdir. İşçi (2008), Elma içkurdu (C. pomonella)'nun erginlerinin Isparta ili elma bahçelerinde eşeysel çekici tuzaklarda ilk yakalanı̧̧ının üst üste iki yıl mayıs ayının ilk haftasında gerçekleştiğini tespit etmiştir. Özpınar ve ark. (2009), Çanakkale ilinde Elma içkurdunun yayılış alanı ve popülasyon gelişimi üzerinde yaptıkları bir çalışmada, ilk ergin çıkışının nisan ayında gerçekleştiğini bildirmişlerdir. Mamay ve Yanık (2013), Şanlıurfa'da elma bahçelerinde $C$. pomonella'nın popülasyon gelişiminin belirlenmesi üzerine yapmış oldukları çalışma sonucunda zararlı erginlerinin Nisan ayının son haftasında tuzaklarda yakalandığını ve ergin uçuş periyodunun doğada yaklaşı 5 ay sürdüğünü, Eylül ayının üçüncü haftasına kadar erginlerin doğada bulunduklarını ifade etmişlerdir. Ayrıca ergin popülasyonunun oluşturduğu tepe noktaları dikkate alındığında zararının 3 döl verebildiğini de belirtmişlerdir. Bayraktar (2015), Karaman ili elma bahçelerinde $C$. pomonella erginlerinin ilk olarak Nisan ayının son haftasında tuzaklarda yakalandığını ve son erginlerin ise Ağustos ayının ikinci haftasında eşeysel çekici tuzaklarda yakalandığını tespit etmiştir. Kaplan ve Bayram (2019), Bingöl ili elma bahçelerinde Elma içkurdunun popülasyon gelişimi ve kısa biyolojisi üzerine yapmış oldukları çalışma sonucunda zararlı erginlerinin eşeysel çekici tuzaklarda ilk olarak Haziran ayının ilk haftasında yakalandığını, ergin uçuş periyodunun doğada 3.5 ay kadar sürdüğünü ve tuzakta son erginlerin Eylül ayının ikinci haftasında yakalandığını ifade etmişlerdir. Araştırıcılar, ergin popülasyonunun oluşturduğu tepe noktalarını dikkate alarak zararlının Bingöl koşullarında 2 döl verebildiğini de belirtmişlerdir. Ayrıca Elma Entegre Mücadele Teknik Talimatı (Anonim 2011)'na göre ilkbaharda ergin çıkışlarının genellikle mayıs ayında (bazı yıllar Nisan ayı ortalarında) başladı̆̆ı ve temmuz ortalarına kadar devam ettiği ifade edilmektedir.

Elma bahçelerinde çalışma süresince en yaygın ve yoğun olarak tespit edilen yaprakbiti türü olan Elma yeşil yaprakbiti $(A$. pomi)'nin, Erzincan ilinde vejetasyon dönemi olan Mayıs-Ekim ayları boyunca doğada görüldüğü saptanmıştır. Zararlının özellikle elma ağaçlarının uç sürgünlerinde ve taze yaprakların alt yüzeylerinde yoğun koloniler oluşturduğu, buralarda beslenerek ağacın zayıflamasına yol açtığı tespit edilmiştir. Alaserhat (2015), Elma yeşil yaprakbitinin, Erzincan ve Gümüşhane illerinde Mayıs-Ekim aylarında konukçuları olan başta elma (Malus communis L.) olmak üzere, armut (Pyrus communis L.) ve ayva (Cydonia oblonga Miller) ağaçları üzerinde bulunduğunu ifade etmiştir. Bazı araştırmacılar tarafından A.pomi’nin, elma yetişen bölgelerde yaygın olarak bulunduğu, genellikle genç fidanlarda zarar yaptığı, sürgünlerin uç kısımlarında ve taze yaprakların alt yüzeylerinde beslendikleri, zararlının bulunduğu yapraklarda enine, hafifçe kıvrılmalara yol açtığı ve popülasyonun yoğun olduğu fidanlarda gelişmenin durduğu bildirilmektedir (Tuatay, 1993; Blackman ve Eastop, 1994; Toros ve ark., 2002). Ayrıca Elma yeşil yaprakbitinin, Lahana siyah halkalı leke (Cabbage black ring spot) ve soğan sarı cücelik (Onion yellow dwarf) virüslerini nonpersistent yolla naklettiği de belirtilmiştir (Kennedy et al., 1962).

İki noktalı kırmızı örümcek (T. urticae) ergin ve nimfleri elma bahçelerinde, Mayıs ayının son haftasından itibaren yapraklarda ilk olarak görülmüş, sıcaklıkların yükseldiği Temmuz ayında popülasyonu yükselmiş ve önemli bir zararlı olarak belirlenmiştir. Kırmızı örümcekler, elma ağaçlarının yapraklarında bitki özsuyunu emerek, yapraktaki klorofillerin parçalanmasına ve dolayısıyla fotosentezin engellenmesine yol açarak zarar oluştururlar. Bu beslenme sonucunda ağacın yapraklarında önce beyaz, sonra sarı ve daha sonra kahverengi lekeler oluşur. Bu lekeler birleşerek yaprağın kuruyup dökülmesine, meyvelerin güneş yanıklığına maruz kalmasına yanı sıra ürün kaybına neden olur. Bozbek ve Gökçe (2000), Doğu Anadolu Bölgesinde Elma Bahçelerinde Entegre Mücadele kapsamında yürüttükleri çalışma sonucunda T. urticae'nın, Mayıs ayının son haftasından itibaren elma yapraklarında görüldüğünü ve Temmuz ayında popülasyonun eşik seviyesini (8-10 adet/yaprak) geçtiğini ve ilaçlama için gereken yoğunluğa ulaştığını belirtmişlerdir. Kaplan (2019), Diyarbakır ili kiraz bahçelerinde İki noktalı kırmızı örümcek (T. urticae) erginlerinin iklim koşullarına bağlı olarak nisan ayının ikinci veya üçüncü haftasında yapraklarda ilk olarak görüldüğg̈nü ve önemli bir zararlı olduğunu ifade etmiştir. Kaplan ve Yücel (2014), Elazığ ili çilek alanlarında kırmız örümceklerin yaygınlık ve yoğunluk açısından önemli bir zararlı olduğunu bildirmişlerdir.

Elma bahçelerinde çiçeklenmenin başlamasıyla Baklazınnı (T. hirta) erginleri, iklim koşullarına bağlı olarak mayıs ayının ikinci haftasında itibaren içerisinde su olan mavi leğen tuzaklarda görülmüş, mayıs ayının üçüncü haftasında ergin sayısı en yüksek düzeye çıkmış ve son olarak mayıs ayının son haftasına kadar erginler tuzaklarda görülmüştür. Bu zararlı doğrudan çiçeklerde beslenerek zarar oluşturmaktadır. Erden (1988), Erzincan bölgesi (Erzincan, Sivas, Gümüşhane, Tunceli-Pertek, Erzurum-İ̀spir ve KarsKağızman) yumuşak çekirdekli meyve ağaçlarında yapmış olduğu çalışma sonucunda tespit ettiği zararlı türlerden olan T. hirta'nın, önemli zararlılardan olduğunu ve Erzincan ilinde elma plantasyonlarında çiçek döneminde yoğun olarak bulunduğunu belirtmiştir. 
Ayrıca zararlının polifag olduğunu, erginlerinin taş ve yumuşak çekirdekli meyve ağaçlarında çiçekleri yemek suretiyle zararlı olduğunu saptamıştır. Çınar ve ark., (2004) T. hirta'nın kirazlarla beslendiğini, Ulusoy ve ark. (1999) bu türün kirazlar için ekonomik olduğunu bildirmiştir. Kaplan (2019), Diyarbakır ili kiraz bahçelerinde T. hirta erginlerinin doğrudan çiçeklerde beslenerek zarar oluşturduğunu, kiraz bahçelerinde çiçeklenmenin başlamasıyla birlikte nisan ayının ilk haftasında itibaren tuzaklarda görüldüğünü nisanın ortalarına doğru ergin sayısının en yüksek düzeye çıktı̆̆ını ve son olarak mayıs ayının ilk haftasına kadar erginlerin tuzaklarda görüldüğünü ifade etmiştir.

Önemli zararlı türlerden bir diğeri olan Elma gözkurdu (A. pomorum), elmanın fenolojisine göre değişmekle birlikte Erzincan ilinde tomurcuk-çiçek dönemi olan nisan sonu-mayıs başı döneminde doğada yoğun olarak görülmüştür. Kışladığı yerlerden çıkan erginlerin elma ağaçlarının açmakta olan tomurcukları ile beslendiği ve daha sonra çiftleşen dişilerin yumurtaların çiçek tomurcuklarına bıraktıkları saptanmıştır. Güçlü ve Özbek (1995), Erzurum ili elma ağaçlarında yürüttükleri çalışma sonucunda önemli düzeyde zarar yapan bir diğer türün de elma gözkurdu A. pomorum olduğunu ve çiçek tomurcuklarındaki zararının ortalama \%26 (2030) oranında olduğunu tespit etmiş̧lerdir. Araştırıcılar zarar görmüş taç yaprakların kırmızı-kahverengi renkte olduğu, zarar görmüş gözlerin biraz kabardıktan sonra açılmadığını saptamışlardır. Ayrıca bu gözlerin içerisine bakıldığında, göz kurdu larvası veya pupasının bulunduğunu da ifade etmişlerdir. Elma Entegre Mücadele Teknik Talimatı (Anonim 2011)'na göre zararlının kışı ağaç kabukları, yaprak altları veya toprağın yarık ve çatlaklarında geçirdiği, günlük ortalama sıcaklığın $10-11^{\circ} \mathrm{C}$ 'yi bulduğu dönemlerde erginlerin çıkış yaptığı, Şubat 15 'ten Mart ayı sonuna kadar erginlerin ağaçların açmakta olan tomurcuk, filliz ve sürgünleri ile beslendiği, bir dişinin 25 yumurta bıraktığı, larvaların 2-4 haftada gelişerek çiçek içerisinde pupa olduğu ve yılda 1 döl verdiği ifade edilmiştir. Ayrıca zararlının larvaları çiçek tomurcukları içerisinde beslenip geliştikleri için zarar gören çiçeklerin açılmadığı ve meyve bağlamadığı da belirtilmiştir.

\section{Sonuç}

Erzincan ili elma ağaçlarında fitofag ve faydalı türler ile önemli bazı türlerin doğada görülme zamanı belirlemek amacıyla yürütülen bu çalışma sonucunda fitofag türlerden 25 böcek ve 1 akar ile genel predatör ve parazitoitlerden olan 21 faydalı böcek türü saptanmıştır.

Elma bahçelerinde saptanan zararlı türden en yoğun olarak Lepidoptera takımından $C$. pomonella başta olmak üzere 4 adet Tortricidae türü belirlenmiştir. Söz konusu türlerden olan ve elmanın ana zararlısı olan C. pomonella'nın erginleri Mayıs ayının ikinci haftasında itibaren elma ağaçlarında görülmüş olup ergin kelebeklerin elma bahçelerinde uçuş periyodu yaklaşık olarak 4 ay kadar sürmüştür. Çalışma süresince en yaygın ve yoğun olarak tespit edilen yaprakbiti türü olan Elma yeşil yaprakbiti (A. pomi), vejetasyonun dönemini içine alan Mayıs-Ekim ayları boyunca elma ağaçlarının uç sürgünlerinde ve taze yaprakların alt yüzeylerinde yoğun koloniler oluşturmuş ve beslenmiştir. Tetranychus urticae'nın ergin ve nimfleri Mayıs ayının son haftasından vejetasyon sonuna kadar olan dönemde elma bahçelerinde tespit edilmiş olup, yapraklarda bitki özsuyunu emerek zararlı olduğu belirlenmiştir. Baklazınnı olarak belirtilen T. hirta erginleri Mayıs ayının ikinci haftasından mayısın sonuna kadar olan çiçeklenme döneminde elma bahçelerinde bulunmuştur. Erzincan ili elma bahçelerinde bulunan önemli zararlı türlerden bir diğeri olan Elma gözkurdu ( $A$. pomorum) ise tomurcuk-çiçek dönemi olan Nisan sonu-Mayıs başı döneminde yoğun olarak elma bahçelerinde görülmüştür.

Günümüzde insan sağlığının, çevrenin ve biyolojik çeşitliliğin korunması ön planda tutulmaktadır. Modern bir yaklaşımla, zararlı türlerle mücadelede tüm faktörlerin çevresiyle birlikte düşünülmesi gerekir. Elma bahçelerinde zararlılarla birlikte faydalı türlerinin de yaygın olduğu alanlarda uygulanacak mücadele yöntemlerinde geniş spektrumlu kimyasal ilaç ve gereksiz ilaçlamalardan kaçınılması önerilir. Çünkü biyolojik mücadele kapsamında, yararlı türler korunduğu ve etkinlikleri artırıldığı sürece entegre mücadele açısından önemli adımlar atılmış olacaktır. Neticede "Entegre mücadele" programlarının ilk basamağı mevcut faunanın belirlenmesidir. Diğer çalışmalar ancak bu aşamadan sonra yapilabilmektedir.

Elma bahçelerindeki zararlı türler elma ağaçlarının sürgün, yaprak, tomurcuk, çiçek ve meyvelerinde beslenerek verim ve kaliteyi düşürmektedir. Meyve bahçelerinde zararlı türler ile mücadelede gelişi güzel pestisit kullanımının artmasıyla canlılar arasında var olan doğal denge bozulacak, buda ileriki yıllarda zararlıların salgın yapma ihtimalini arttıracaktır. Nitekim elma bahçelerinde belirlenen zararlı türler ile mücadelede başarılı olmak için öncelikle doğada var olan faydalı türlerin belirlenmesi, korunması ve etkinliklerinin artırılması amacıyla ilaçlama zamanı ve sayısı yönünde elde edilmiş olan bilgiler elma üreticileri ile paylaşılacaktır. Böylece gereksiz ilaçlamaların önüne geçilerek üründeki kalite ve verim kaybı yanı sıra kalıntı nedeniyle tüketimde ve ihracatta sorun yaşanmayacak ve sağlıklı bir şekilde elma tüketilebilecektir.

\section{Teşekkür}

Çalışmalarımda elde etmiş olduğum, Coccinellidae teşhisleri Prof. Dr. Nedim UYGUN (Çukurova Üniversitesi, Ziraat Fakültesi, Bitki Koruma Bölümü, Adana), Chamaemyiidae ve Syrphidae teşhisleri Prof. Dr. Rüstem HAYAT (Akdeniz Üniversitesi Ziraat Fakültesi, Bitki Koruma Bölümü, Antalya), Chrysopidae teşhisleri Prof. Dr. Ali SATAR (Dicle Üniversitesi Fen Fakültesi, Biyoloji Bölümü, Diyarbakır), Anthocoridae ve Miridae teşhisleri Dr. Gülten YAZICI (Zirai Mücadele Merkez Araştırma Enstitüsü Müdürlüğü, Ankara), Lepidoptera teşhisleri Dr. Mustafa ÖZDEMIR (Zirai Mücadele Merkez Araştırma Enstitüsü Müdürlüğü, Ankara), Dermaptera teşhisi Prof. Dr. Ali DEMIRSOY (Hacettepe Üniversitesi), Aphelinidae teşhisi Prof. Dr. Mikdat DOĞANLAR (Mustafa Kemal Üniversitesi, Bitki Koruma Bölümü) ve Braconidae teşhisleri Doç. Dr. Coşkun GÜÇLÜ (Eskişehir Osmangazi Üniversitesi, Ziraat Fakültesi, Tarımsal Biyoteknoloji Bölümü) tarafından yapılmış olup, tüm hocalarıma teşekkürlerimi sunarım.

Ayrıca Tarım ve Orman Bakanlığı, Tarımsal Araştırmalar ve Politikalar Genel Müdürlüğü’ne teşekkürü bir borç bilirim. 


\section{Kaynakça}

Alaserhat, (2015). Erzincan ve Gümüşhane İllerinde Yetiştirilen Ilıman İklim Meyve Türlerinde Bulunan Aphididae (Hemiptera) Türleri, Yoğunlukları, Doğal Düşmanları ve Sekonder Konukçularının Belirlenmesi. Atatürk Üniversitesi Fen Bilimleri Enstitüsü, Doktora Tezi (yayınlanmamış), Erzurum, $320 \mathrm{~s}$.

Alaserhat, İ., Güçlü, Ş., (2016). Survey of Aphid Species (Hemiptera: Aphididae) and Their Associated Parasitoid And Predator Species on Rosa spp. in Turkey. Egyptian Journal of Biological Pest Control, 26 (4): 849-850.

Alaserhat, İ., Canbay, A., (2017). Aphididae Species, Their Parasitoids, Predators, and Parasitism Rates on Pepper (Capsicum annuum L.). Entomological News, 127 (1), 36-50.

Alaserhat, İ., Kaplan, M., (2017). Ovacık (Tunceli) ilçesindeki Akasyalarda (Robinia spp.) Bulunan Zararlı ve Faydalı Böcek Türleri. Türkiye Entomoloji Bülteni, 7 (3): 21-28.

Anonim, (2008). Zirai Mücadele Teknik Talimatları. Tarım ve Orman Bakanlığı, Tarımsal Araştırmalar ve Politikalar Genel Müdürlüğü Yayınları, Ankara, Cilt 3: 322 s.

Anonim, (2011). Elma Entegre Mücadele Teknik Talimatı. Tarım ve Orman Bakanlığı, Tarımsal Araştırmalar ve Politikalar Genel Müdürlüğü Yayınları, Ankara, 188s.

Anonymous, (2017). FAO (Food Agriculture Organization) (http://www.fao.org/faostat/en/\#data/QC) (Erişim Tarihi: 13.11.2019)

Ayaz, T., Yücel, A., (2010). Elazı̆̆ İli Elma Alanlarında Zararlı ve Yararlı Arthropod Türlerinin Belirlenmesi Üzerine Araştırmalar. Harran Tarım ve Gida Bilimleri Dergisi, 14 (1): 9-16.

Bayraktar, S.Y., (2015). Karaman İlinde Elma Bahçelerinde Elma İçkurdu İle Kimyasal Mücadelede Mücadele Zamanının Belirlenmesine Yönelik Çalışmalar. Namık Kemal Üniversitesi Fen Bilimleri Enstitüsü, Yüksek Lisans Tezi (yayınlanmamış), Tekirdağ, $35 \mathrm{~s}$.

Blackman, R.L., Eastop, V.F., (1994). Aphids on The World's Trees: An Identification and information quide CAB International. Department of Entomology The Natural History Museum, 986+16 p, London, England.

Bora, T., Karaca, İ., (1970). Kültür Bitkilerinde Hastalığın ve Zararın Ölçülmesi. Ege Üniversitesi Ziraat Fakültesi, Yardımcı Ders Kitabı, Yayın no:167, 43 s.

Bozbek, Ö., Gökçe, A.Y., (2000). Doğu Anadolu Bölgesinde Elma Bahçelerinde Entegre Mücadele Araştırma, Uygulama ve Egitim Projesi. Tarımsal Araştırmalar ve Politikalar Genel Müdürlüğü, Erzincan Bahçe Kültürleri Araştırma Enstitüsü Müdürlüğü Yayınları, No: 36, 45 s., Erzincan.

Bozbek, Ö., Kütük, Y., Alıcı, H., Çakırbay, İ.F., Canbay, A., (2009). Erzincan'da Elma Pamuklubiti (Eriosoma lanigerum (Hausmann) (Hemiptera: Pemphigidae)'nin Yayılışı, Yoğunluğu, Parazitoit ve Predatörlerinin Tespiti. III. Bitki Koruma Kongresi, Van.

Bozbek, Ö., (2012). Erzincan ilinde elma ağaçlarında görülen Coccoidea (Hemiptera) türleri ile bunların parazitoit ve predatörleri. Atatürk Üniversitesi Fen Bilimleri Enstitüsü, Yüksek Lisans Tezi (yayınlanmamış), Erzurum, $60 \mathrm{~s}$.

Bulantekin, Ö., Kuşçu, A., (2017). Elmada bulunan fitokimyasallar ve diğer zengin bileşenlerin insan sağlığına yararları. Meyve Bilimi, 1: 213-218.

Canbay, A., Tozlu, G., (2013). Erzincan ilinde elma ağaçlarında zarar yapan Archips (Lepidoptera: Tortricidae) türlerinin tespiti, popülasyon değişimleri ile önemli tür Archips rosana (L., 1758)'nın biyolojisi. Türkiye Entomoloji Dergisi, 37 (3): 305-318.

Cranshaw, W., (2004). Biological Controls IX. Insect Predators. http://highplainsippm.org

Çınar, M., Çimen, İ., Bolu, H., (2004). Elazığ ve Mardin İlleri Kiraz Ağaçlarında Zararlı Olan Türler, Doğal Düşmanları ve Önemlileri Üzerinde Gözlemler. Türkiye Entomoloji Dergisi, 28 (3): 213-220.

Çiftçi, K., Türkyılmaz N., Kumaş, F. ve Özkan, A., (1985). Antalya İli Elma Bahçelerindeki Önemli Zararlılar ile Doğal Düşmanlarının Tespiti Üzerinde Ön Çalışmalar. Bitki Koruma Bülteni, 25 (1-2), 49-61.

Çiftçi, K., Özkan, A., Türkyılmaz, N., (1995). Antalya İli Elma Zararlılarının Biyolojik Mücadele İmkânlarının Araştırılması. Bitki Koruma Bülteni, 35 (1-2): 45-61.

Düzgüneş, Z., Toros, S., 1978. Ankara ili ve çevresinde elma ağaçlarında bulunan yaprakbiti türleri ve kısa biyolojileri üzerinde araştırmalar. Türkiye Bitki Koruma Dergisi, 2 (3): 151-175.

Erden, F., (1988). Erzincan Bölgesi Yumuşak Çekirdekli Meyve Ağaçlarının Böcek Kökenli Zararlılarının Tanınmaları ve Önemlilerinin Zararlılık Durumları Üzerinde Araştırmalar. Tarım ve Orman Bakanlığı, Tarımsal Araştırmalar ve Politikalar Genel Müdürlüğü Yayınları, Ankara, Yayın no: 4, 96 s.

Grigorov, S.P., (1974). Karantina na Restaniata. Zemizdat, Sofya, 346 pp.

Güçlü, Ş., Özbek, H., (1995). Erzurum'da Elma Ağaçlarında Çiçek ve Meyvedeki Zararlılar Üzerinde Bazı Gözlemler. Atatürk Ünivesitesi Ziraat Fakültesi Dergisi, 26 (2): 171-175.

İren, Z., (1977). Önemli Meyve Zararlıları, Tanınmaları, Zararları, Yayılışları ve Mücadele Metodları. Tarım ve Orman Bakanlığı, Tarımsal Araştırmalar ve Politikalar Genel Müdürlüğü Yayınları, Ankara, 167s.

İşçi, M., (2008). Elma İçkurdu (Cydia pomonella Lep.: Tortricidae)'nun Farklı Elma Çeşitlerindeki Zarar Oranlarının Belirlenmesi. Selçuk Üniversitesi Fen Bilimleri Enstitüsü, Yüksek lisans tezi (Basılmamış), Konya.

Kaplan, E., Bayram, Y., (2019). Bingöl İli Elma Bahçelerinde Elma İçkurdu [(Cydia pomonella) (L.) (Lepidoptera: Tortricidae)]'nun popülasyon gelişimi ve kısa biyolojisi. Mustafa Kemal Üniversitesi Tarım Bilimleri Dergisi, 24 (2): 123-128.

Kaplan, M., Bayhan, E., (2014). Mardin İli Bağ Alanlarında Thripslerle Birlikte bulunan Doğal Düşmanlar. Uluslararası Mezopotamya Tarım Kongresi, (22-25 Eylül 2014), 176 s., Diyarbakır.

Kaplan, M., Yücel, A., (2014). Elazığ İli Çilek Alanlarında Belirlenen Zararlı Böcek ve Akar Türleri, Meyve Bilimi Dergisi, 1 (2): 7 14. 
Kaplan, M., Özgen, İ., Ayaz, T., (2016). Mardin İli Zeytin Bahçelerinde Zeytin Pamuklubiti [Euphyllura straminea Loginova (Hemiptera: Psyllidae)]'nin Doğal Düşmanları ve Önemli Türlerin Popülasyon Değişimi. Harran Tarım ve Gıda Bilimleri Dergisi, 20 (3): 175-182.

Kaplan, M., (2019). Diyarbakır İli Bazı Kiraz Bahçelerinde Bulunan Zararlı ve Faydalı Böcek Türleri ile Bazı Önemli Zararlı Türlerin Doğada Görülme Zamanı. Avrupa Bilim ve Teknoloji Dergisi, 17: 283-289.

Karaca, G., Karaca, I., Yardımcı, N., Demirözer, O., Aslan, B., Çulal Kiliç, H., (2010). Investigations on pests, diseases and present early warning system of apple orchards in Isparta, Turkey. African Journal of Biotechnology, 9 (6): 834-841.

Karamürsel, D., (2009). Türkiye elma endüstrisine genel bir bakış. Tarım Türk Dergisi, (15): 13-14.

Kaya, Ü., Öncüer, C., (1988). Laboratuvarda Üretilen Chrysoperla carnea (Steph.) (Neuroptera: Chrysopidae)'nın Biyolojisine Farklı İki Besinin Etkisi Üzerinde Bir Araştırma. Türkiye Entomoloji Dergisi, 12 (3): 151-159.

Kennedy, J.S., Day, M.F., Eastop, V.F., (1962). A Conspectus of Aphids as Vector of Plant Viruses Commonwealth. Inst. Ent., 114 p, London, England.

Kıroğlu, H., Aykaç, K.M., Ergüder, M.T., Çamlıdere, R., Kılıç, M., Çevik, T., (1992). Karadeniz Bölgesi Elma Bahçelerinde Entegre Savaş Olanakları Üzerine Çalışmalar. Tarım ve Orman Bakanlığı, Tarımsal Araştırmalar ve Politikalar Genel Müdürlüğü Yayınları, Yayın no: 21-22, Ankara

Küçükballı, N., Karaca, İ., (2018). Elma Bahçelerinde Bazı Önemli Zararlılara Karşı Azadirachtin ve Kaolin Uygulamalarının Etkisi. Süleyman Demirel Üniversitesi Fen Bilimleri Enstitüsü Dergisi, 22 (2): 918-923.

Mamay, M., Yanık, E., (2013). Şanlıurfa'da Elma Bahçelerinde Elma İçkurdu [Cydia pomonella (L.) (Lepidoptera: Tortricidae)]'nun Populasyon Gelişimi ve Farklı Metotlar Kullanılarak Bulaşıklık Oranının Belirlenmesi. Tarım Bilimleri Dergisi, 19: 113-120.

Mdellel, L., Ben Halima Kamel, M., (2015). Apple Aphid's Species and Their Natural Enemies in Tunisian Orchards. Jornal of New Sciences, 24 (4): 1108-1114.

Öncüer, F., (1991). Türkiye Bitki Zararlısı Böceklerin Parazit ve Predatör Kataloğu. Ege Üniversitesi Ziraat Fakültesi Yayınları No: 505 , İzmir, $281 \mathrm{~s}$.

Özbek, H., Güçlü, Ş., Hayat, R., Yıldırım, E., (1998). Meyve, Bağ ve Bazı Süs Bitkileri Zararlıları. Atatürk Üniversitesi Ziraat Fakültesi Yayınları, Yayın no: 323, 357s, Erzurum

Özdemir, Y., Özdemir, M., (2002). Orta Anadolu Bölgesinde Archips Türlerinde (Lep.:Tortricidae) Saptanan Ichneumonidae (Hym.) Türleri. Bitki Koruma Bülteni, 42 (1-4): 1-7.

Özkan, A., (1986). Antalya ve Çevresi Yumuşak Çekirdekli Meyve Agaçlarının Coleoptera ve Heteroptera Takımlarına Ait Faydalı Böcek Türleri, Tanınmaları, Konukçulan ve Önemlilerinin Etkinlikleri Üzerinde Araştırmalar. Tarım ve Orman Bakanlığı, Tarımsal Araştırmalar ve Politikalar Genel Müdürlüğü, Antalya Biyolojik Mücadele Araştırma Enstitüsü Yayınları, Yayın no: 5, Antalya

Özpınar, A., Şahin, A.K., Polat, B., (2009). Çanakkale İlinde Elma İçkurdu [Cydia pomonella (L.) (Lepidoptera: Tortricidae)]'nun Yayılış Alanı ve Popülasyon Gelişmesinin Belirlenmesi. Türkiye III. Bitki Koruma Kongresi Bildirileri (15-18 Temmuz 2009), 100 s., Van.

Piekarska-Boniecka, H., Wilkaniec, B., Dolan'Ska-Niedbała, E., (2008). Parasitoids of Ichneumonidae Family (Hymenoptera, Apocrita) Limiting Abundance of Rose Tortrix Moth Archips rosana (L.) in Selected Orchards in Wielkopolska. Progress in Plant Protection, 48 (4): 1319-1322.

Porcel, M., Andersson, G.K.S., Pålsson, J., Tasin, M., (2018). Organic Management in Apple Orchards: Higher Impacts on Biological Control than on Pollination. Journal of Applied Ecology, 55: 2779-2789.

Toros, S., Uygun, N., Ulusoy, R., Satar, S., Özdemir, I., (2002). Doğu Akdeniz Bölgesi Aphidoidea Türleri. T.C. Tarım ve Orman Bakanlığı, Tarımsal Araştırmalar ve Politikalar Genel Müdürlüğü, 108 s, Ankara.

Tuatay, N., (1993). Türkiye Yaprakbitleri (Hemiptera: Aphididae) IV. Aphidinae: Aphidini (I. Kısım). Bitki Koruma Bülteni, 33 (3-4): $83-106$.

Ulusoy, M.R., Vatansever, G., Uygun, N., (1999). Ulukışla (Niğde) ve Pozantı (Adana) Yöresinde Kirazlarda Zararlı Olan Türler, Doğal Düşmanları ve Önemlileri Üzerindeki Gözlemler. Türkiye Entomoloji Dergisi, 23 (2): 111-120.

Yaman, Y., Yorulmaz Salman, S., Ay, R., (2016). Isparta İli Elma Bahçelerinden Toplanan Panonychus ulmi Koch'nin Bazı Akarisitlere Karşı Duyarlılık ve Detoksifikasyon Enzim Düzeyleri. Tarım Bilimleri Dergisi, 22: 249-260.

Yanar, D., Ecevit, O., (2005). Tokat İlinde Elma (Malus communis L.) Bahçelerinde Görülen Bitki Zararlısı ve Predatör Akar Türleri. Anadolu Tarım Bilimleri Dergisi, 20 (1): 18-23.

Yardım, E., Atlıhan, R., Özgökçe, M.S., Kaydan; M.B., Özgen, İ., (2003). Elma Bahçelerinde Elma İçkurdu [Cydia pomonella (L.)] İçin Kitlesel Tuzaklama ve Kimyasal Mücadelenin Bazı Etkileri. Yüzüncü Yıl Üniversitesi, Ziraat Fakültesi, Tarım Bilimleri Dergisi, 13 (1): 45-48.

Yiğit, A., Uygun, N., (1982). Adana, İçel ve Kahramanmaraş İlleri Elma Bahçelerinde Zararlı ve Yararlı Faunanın Saptanması Üzerinde Çalı̧̧malar. Bitki Koruma Bülteni, 22 (4): 163-178.

Yoldaş, Z., (1994). İki Farklı Avla Beslenen Chrysoperla carnea (Stephens) (Neuroptera: Chrysopidae)'nın Biyolojisi Üzerinde Araştırmalar. Türkiye 3. Biyolojik Mücadele Kongresi Bildirileri (25-28 Ocak 1994), 375-380 s., İzmir.

Zeki, C., Demir, T., Kılı̧, M., Kural, İ., Çakır, O., Tokgönül, S., Hepdurgun, B., Çalı, S., Aydogdu, S., (1998). Elma Bahçelerinde Entegre Mücadele Teknik Talimatı. Tarım ve Orman Bakanlığı, Tarımsal Araştırmalar ve Politikalar Genel Müdürlüğü Yayınları, Ankara, $81 \mathrm{~s}$. 